\title{
Model of Tools for Requirements Elicitation Process for Children's Learning Applications
}

\author{
Mira Kania Sabariah ${ }^{1}$ \\ Department of Electrical and Information Engineering \\ Universitas Gadjah Mada, Yogyakarta \\ Indonesia \\ School of Computing \\ Telkom University, Bandung \\ Indonesia
}

\author{
Paulus Insap Santosa ${ }^{2}$ \\ Department of Electrical and Information Engineering \\ Universitas Gadjah Mada, Yogyakarta, Indonesia \\ Ridi Ferdiana ${ }^{3}$ \\ Department of Electrical and Information Engineering \\ Universitas Gadjah Mada, Yogyakarta, Indonesia
}

\begin{abstract}
Requirements Elicitation are the initial stages in the application development process, where a set of needs from the system will be built and obtained by communicating with stakeholders who have a direct and indirect influence on those needs. Failure in the requirements elicitation process was caused by weak communication. Communication is an essential thing in carrying out the requirements elicitation process. The selection of the right elicitation technique is not only a solution. Informants as sources of information on requirements also need to be considered. The choice of the correct technique often fails because of the tools not useful. The availability of the right form of equipment needs to be considered so that the communication between the elicitation team and the informant goes well. Children have characteristics not the same as adults. Limitations in terms of psychomotor, cognitive, and emotional children are considered in choosing elicitation techniques and tools. These limitations are also influenced by the age range of child development. The use of digital elicitation devices is recommended to be used in the requirements elicitation process. The presentation of interactive tools makes it easier for children to convey their desires. In learning applications for children, aspects of pedagogy that need to be explored are learning styles and children's thinking abilities. Every child in every age range has a different preference for learning style. That is because children do not have learning experiences. That also applies to the level of thinking ability of children. Therefore, these two things need to be appropriately explored when the learning application development process. The proposed elicitation tool model was made by taking into account both components of that pedagogical aspects. The test results of the built model show that the application has satisfaction. That means that children can communicate well in conveying the needed as requirements to the learning application.
\end{abstract}

Keywords-Requirements elicitation; communication; children learning application; pedagogical aspect; learning style

\section{INTRODUCTION}

Requirements elicitation are the initial stages in the application development process, where a set of needs from the system will be built and obtained by communicating with stakeholders who have a direct and indirect influence on these needs [1]. According to Rupp, $60 \%$ of failures in the software development process occur due to requirements elicitation [2].
Failure in the requirements elicitation process was caused by difficulties in communicating between humans[3]. Ambiguity in communication often causes obstacles in transferring knowledge that causes documentation of needs to be incomplete and clear [4]. Communication is a relational process in creating and interpreting a message to get a response [5]. Communication is not just an expression but also persuasion, control, and influence in meetings between two people, or communication between two people with the existence of feedback and the role of the speaker and listener alternately. Then an interaction occurs [6].

Documentation of needs tends to be in the form of face to face communication [7]. Other problems, if there is no documentation related to software requirements specifications, will cause the requirements quality assurance (QA) process of the application to be built into a difficult one [8]. In many cases, the selection of elicitation methods or techniques was not based on application content or the strength of elicitation techniques but only based on a tradition, or that is deemed familiar by the developer [9].

The requirements elicitation process can run effectively if the developers have good expertise and knowledge in choosing an elicitation technique [10]. In many cases, the selection of elicitation methods or techniques was not based on application content or the strength of elicitation techniques. Sometimes only based on a tradition or that is deemed familiar by the developer [9]. Also, many developers in practice do not pay attention to requirements elicitation techniques [11]. Another thing that causes the failure of a requirements elicitation technique is the way of communication that is not by the level of knowledge of users [12], [13]. User involvement in the elicitation process is a factor of success in selecting elicitation techniques [14] and fulfills the usability of the applications built [15].

In the construction of children's learning applications, children's involvement in the elicitation process was almost never done. The current phenomenon, the involvement of children as users in the application development process, is often emphasized only at the testing stage so that sometimes the idea of the application being built is still determined by the developer [16]. By involving children in the elicitation process, 
of course, we need to pay attention not only to their elicitation techniques but also to consider the tools used in exploring the needs of the applications to build. Also, the direct involvement of children in the elicitation process can have a positive impact on children in using the learning products produced [17].

The objectives of this research are two, including (i) identify the form of media the right communication tool to assist the elicitation process, (ii) design a model of communication tools that will be used in the elicitation process according to the recommended media form at the first destination.

\section{LITERATURE REVIEW}

User requirements are the highest level in requirements [18], and their contents consist of a set of user desires [19]. Failure to define user requirements will impact the quality and satisfaction of the user of the application. Another thing also has an impact on not achieving the objectives of the software. Elicitation requirements are an initial step in defining requirements, one of which is user requirements. Communication is a general cause of failure in the requirements elicitation process [20].

Communication is a relational process in creating and interpreting a message to get a response [5]. In conducting communication, it is necessary to have feedback and the roles of the speaker and listener who alternately [6], which then occurs an interaction. The interaction process can occur if the message conveyed is understood by both parties. Piaget's convey [17] that children have limited ability in communication in every age range. Cognitive, psychomotor, and emotional are the factors that influence limited ability [18]. These factors certainly affect the requirements elicitation activities.

The different cognitive, psychomotor and, emotional development is certainly a consideration in choosing elicitation techniques. Interview and prototype techniques [21], are recommended as appropriate techniques for child respondents. The selection of appropriate techniques needs to be followed by appropriate tools so that communication can go well. The development of technology has a positive impact on children. This is evidenced by the many uses of technology in children, especially in the learning process [22]. Technology is considered as an interactive media for children in the learning process. Technology that can present audio and visual forms is considered quite effective and efficient in helping children interact.

Effective and efficient interactions and issuing of valid results are needed in the requirements elicitation activities. Agile methodologies that are widely used in the software development process today require these conditions [23]. Rapid iteration and relatively short development time [24], of course, requires the application of an appropriate technique and tool. Documentation of requirements is also a demand that is needed so that the verification and validation process can be done quickly and correctly. The application of digital technology as a tool in conducting requirements elicitation is widely used today. This concept is widely applied to the requirements elicitation framework [19], [25].

\section{METHODOLOGY}

\section{A. Methods}

The research was conducted in two stages. The reason for the two stages is because there are two objectives to be achieved. In the first stage, the data collection process was carried out using interview techniques and literature studies. Interview techniques were carried out using questionnaires and interviews with child learning experts. The questionnaire used was paper and digital. Interviews with experts were conducted to determine the content presented in the questionnaire. In addition to interview techniques, literature studies were also carried out. The keyword was used in the literature review are learning applications, children's characteristics, elicitation requirements, and elicitation techniques. The use of interview techniques and prototypes was based on the results of previous studies related to the best elicitation techniques used when communicating with children [20]. In the second stage, interviews and prototype techniques were carried out. The prototype was built according to the model produced from the results of stage one.

\section{B. Participant}

Participants who will be involved to achieve the first goal are children aged 6-8 years with primary school level education 1-3. To achieve the first goal, participants consisted of 33 children with a gender composition of 18 girls and 15 boys from 3 elementary schools. Meanwhile, to achieve the second goal, 32 participants were involved. The number of participants is adjusted to the limit of quantitative research [21], as many as 30 children.

\section{Material}

The material used in this application is a questionnaire and prototype applications. Two type of questionnaires that will be used in this research. The first questionnaire was given when determining the right form of tool to communicate with children. The second questionnaire was created to measure user satisfaction from the proposed model of tools.

The questionnaire was made to answer the first purpose of this study, which is related to the form of tools that are appropriate for the child's respondent. There are two forms of questionnaires to be used in the data collection process. First is a paper questionnaire, and the second is the digital questionnaire. The questionnaire in digital form was presented in the form of an application.

The content of the two questionnaires is the same, where the difference is only in the form of presentation. The content presented is adjusted to the age of the development stage of the child 6-8 years, which refers to Piaget's. Questions were presented in four types of content, namely color, color in geometry, 2D / 3D geometry, and pictorial objects. Fig. 1 is a sample questionnaire in the form of a paper, and Fig. 2 is one example of a questionnaire in digital form (application). The children were asked to rate each question in the questionnaire with two types of answer choices, namely likes and dislikes. Questionnaires in digital form were built in the form of mobilebased applications. The second questionnaire was made to measure satisfaction from the proposed tool. The questionnaire presents nine questions (P-1-P9) related to user satisfaction. 
Among them are the ease of using the application, ease of using each navigation, helps in choosing colors and objects, ease of reading texts. Likert scale (1-5) was used in the questionnaire.

\section{Measure}

Data measurement results from the first questionnaire were conducted using a non-parametric test with the Wilcoxon approach. This approach was carried out to see the difference between the selection of paper and digital form based on the time value. The second questionnaire using the analysis interval to processing data results.

\section{Mark $\sqrt{ }$ for the selected column What color do you like or dislike?}

\begin{tabular}{|c|c|c|}
\hline Color & Like (@) & Dislike (:) \\
\hline & & \\
\hline & & \\
\hline & & \\
\hline & & \\
\hline & & \\
\hline & & \\
\hline & & \\
\hline & & \\
\hline & & \\
\hline & & \\
\hline
\end{tabular}

Fig. 1. Example of a Paper Questionnaire.

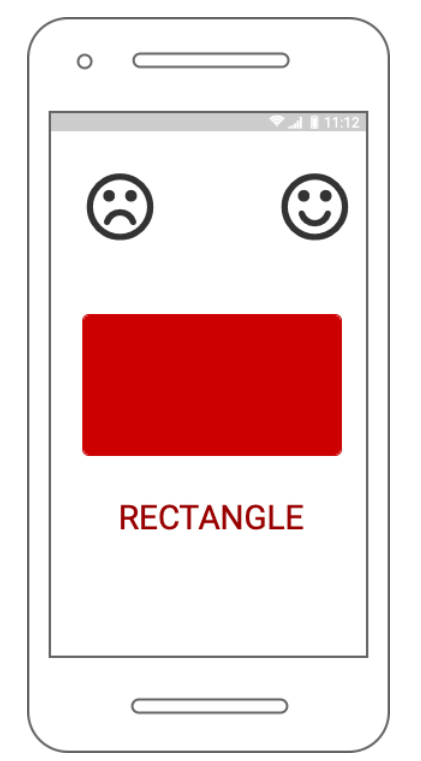

Fig. 2. Example of a Digital Questionnaire (Application).

\section{RESUlt AND Discussion}

This research is divided into two stages, where the first stage is identifying the form of elicitation tools and the second stage is modeling the tools.

\section{A. Identification the form of Requirements Elicitation Tools}

Data retrieval related to the determination of the form of requirements elicitation tools for children's learning applications was carried out on 33 children. Children fill out questionnaires that were presented in the paper and digital forms (apps). Table I shows the results of the processing of the two forms of questionnaires measured based on the interaction time of each respondent in answering each question. Each material was presented in the form of paper and digital. From Table I, there are several things that can be concluded that communication with children tends to be more productive using applications (digital) compared to paper.

The difference between the use of paper questionnaires and digital has a time difference of about 5.91 seconds with an answer correlation value of 0.71 . That was also proven by conducting a non-parametric test using the Wilcoxon approach with 0.003 , as shown in Table III. The results can be concluded that there is a difference between the paper and digital approaches. Thus, the digital approach is more recommended in the process of needs elicitation with child respondents because it has a faster time, as shown in Table II. The use of digital media is also considered to improve children's understanding of the learning process, especially if it was presented in cross-platform forms [22].

\section{B. Proposed Model of Tools for Requirements Elicitation}

Based on the results of data retrieval through interviews and prototypes of the form of instruments recommended in the needs elicitation process is tools in the form of mobile-based applications. The model of elicitation tools built must be adapted to the requirements that need to be explored in building children's learning applications. There are two types of applications that tend to be made for children's education applications based on the results of interviews with five child education application developers in Indonesia. The type of application is in the form of games and simulation (non-game). Both types of applications have different characteristics and approaches to the development process so that the impact on the elicitation application model will be built. Content or problem domain becomes the primary key in the selection to determine the type of application to be made according to the requirements modeling language (RML) approach [23]. The other most crucial component to consider in the learning process is learning styles. VARK learning styles tend to be recommended in children's learning applications. This is because VARK learning styles define learning strategies according to children's sensory preferences, namely, visual, auditory, reading/writing, and kinesthetic [24]. In addition, children in the learning process do not have learning experiences. The content that will be presented in the form of VARK learning styles is also differentiated based on the thinking skills level that refers to Bloom's theory [25]. 
TABLE. I. The Results of Processing Questionnaire DATA using PAPER AND Digital

\begin{tabular}{|c|c|c|c|c|c|c|c|c|}
\hline & Paper & Digital & Paper & Digital & Paper & Digital & Paper & Digital \\
\hline Respondent & Color & Color & $\begin{array}{l}\text { Color } \\
\text { Geometri }\end{array}$ & $\begin{array}{l}\text { Color } \\
\text { Geometri }\end{array}$ & $\begin{array}{l}\text { Geometri } \\
\text { 2D/3D }\end{array}$ & $\begin{array}{l}\text { Geometri } \\
\text { 2D/3D }\end{array}$ & $\begin{array}{l}\text { Pictorial } \\
\text { Object }\end{array}$ & $\begin{array}{l}\text { Pictorial } \\
\text { Object }\end{array}$ \\
\hline A1 & 0,19 & 0,07 & 0,16 & 0,08 & 0,15 & 0,09 & 0,18 & 0,07 \\
\hline A2 & 0,23 & 0,10 & 0,17 & 0,09 & 0,16 & 0,07 & 0,25 & 0,15 \\
\hline $\mathrm{A} 3$ & 0,14 & 0,17 & 0,10 & 0,08 & 0,17 & 0,11 & 0,18 & 0,09 \\
\hline A4 & 0,17 & 0,07 & 0,15 & 0,07 & 0,12 & 0,07 & 0,19 & 0,09 \\
\hline A5 & 0,25 & 0,10 & 0,12 & 0,17 & 0,25 & 0,21 & 0,18 & 0,09 \\
\hline A6 & 0,22 & 0,06 & 0,20 & 0,06 & 0,22 & 0,21 & 0,18 & 0,07 \\
\hline A7 & 0,23 & 0,07 & 0,13 & 0,11 & 0,16 & 0,16 & 0,18 & 0,08 \\
\hline A8 & 0,38 & 0,16 & 0,41 & 0,08 & 0,26 & 0,07 & 0,19 & 0,11 \\
\hline A9 & 0,29 & 0,07 & 0,31 & 0,07 & 0,19 & 0,20 & 0,15 & 0,06 \\
\hline A10 & 0,23 & 0,07 & 0,15 & 0,15 & 0,14 & 0,06 & 0,15 & 0,08 \\
\hline A11 & 0,19 & 0,06 & 0,14 & 0,16 & 0,12 & 0,06 & 0,15 & 0,06 \\
\hline A12 & 0,26 & 0,10 & 0,22 & 0,28 & 0,23 & 0,09 & 0,26 & 0,13 \\
\hline A13 & 0,55 & 0,28 & 0,07 & 0,06 & 0,10 & 0,03 & 0,08 & 0,28 \\
\hline A14 & 0,47 & 0,31 & 0,07 & 0,12 & 0,08 & 0,09 & 0,18 & 0,40 \\
\hline A15 & 0,32 & 0,33 & 0,06 & 0,07 & 0,40 & 0,09 & 0,19 & 0,30 \\
\hline A16 & 0,37 & 0,21 & 0,05 & 0,08 & 0,17 & 0,07 & 0,16 & 0,61 \\
\hline A17 & 0,30 & 0,25 & 0,10 & 0,13 & 0,20 & 0,09 & 0,06 & 0,28 \\
\hline A18 & 0,48 & 0,08 & 0,29 & 0,08 & 0,06 & 0,08 & 0,10 & 0,64 \\
\hline A19 & 1,10 & 0,14 & 0,37 & 0,12 & 0,10 & 0,10 & 0,18 & 0,82 \\
\hline A20 & 0,26 & 0,13 & 0,22 & 0,09 & 0,11 & 0,09 & 0,15 & 0,45 \\
\hline A21 & 0,41 & 0,08 & 0,22 & 0,07 & 0,03 & 0,07 & 0,10 & 0,24 \\
\hline A22 & 0,35 & 0,06 & 0,18 & 0,05 & 0,13 & 0,06 & 0,09 & 0,19 \\
\hline A23 & 0,33 & 0,08 & 0,19 & 0,07 & 0,14 & 0,07 & 0,19 & 0,28 \\
\hline A24 & 0,45 & 0,08 & 0,29 & 0,08 & 0,12 & 0,08 & 0,09 & 0,27 \\
\hline A25 & 0,33 & 0,11 & 0,21 & 0,07 & 0,02 & 0,06 & 0,04 & 0,64 \\
\hline A26 & 0,32 & 0,07 & 0,24 & 0,17 & 0,04 & 0,21 & 0,08 & 0,32 \\
\hline A27 & 0,24 & 0,07 & 0,16 & 0,06 & 0,04 & 0,06 & 0,08 & 0,26 \\
\hline A28 & 1,16 & 0,12 & 0,38 & 0,21 & 0,17 & 0,08 & 0,12 & 0,34 \\
\hline A29 & 0,11 & 0,05 & 0,12 & 0,03 & 0,03 & 0,02 & 0,06 & 0,11 \\
\hline A30 & 0,35 & 0,10 & 0,18 & 0,07 & 0,05 & 0,07 & 0,12 & 0,32 \\
\hline A31 & 0,24 & 0,08 & 0,12 & 0,28 & 0,07 & 0,16 & 0,06 & 0,24 \\
\hline A32 & 0,33 & 0,16 & 0,24 & 0,11 & 0,09 & 0,06 & 0,06 & 0,54 \\
\hline A33 & 0,19 & 0,05 & 0,14 & 0,16 & 0,04 & 0,06 & 0,06 & 0,40 \\
\hline $\bar{\Sigma}$ & 11,44 & 3,52 & 7,19 & 3,49 & 3,75 & 3,41 & 2,97 & 9,02 \\
\hline
\end{tabular}

TABLE. II. COMPARISON OF TIME OF INTERACTION PAPER VS. DigITAL

\begin{tabular}{|l|l|}
\hline Paper & Digital \\
\hline 25,35 & 19,44 \\
\hline
\end{tabular}

TABLE. III. THE RESUlts of THE WILCOXON TEST

\begin{tabular}{|l|l|}
\hline Test Statistics & Digital - Paper \\
\hline & $-2.976^{\mathrm{b}}$ \\
\hline $\mathrm{Z}$ & .003 \\
\hline Asymp. Sig. (2-tailed) & \\
\hline
\end{tabular}




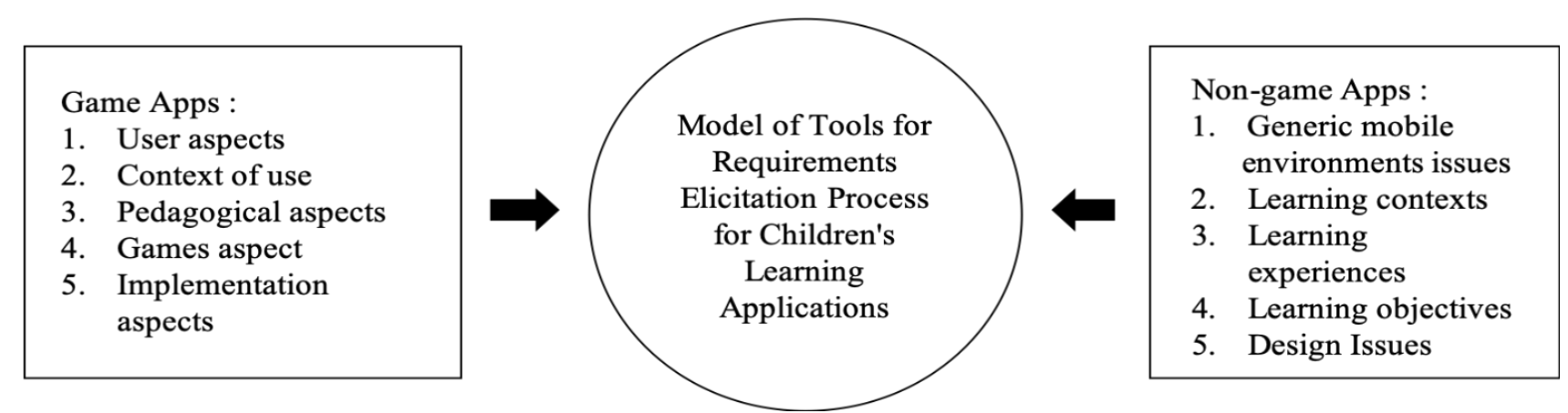

Fig. 3. Model of Tools for Requirements Elicitation Process for Children's Learning Application

The model of tools for requirements elicitation process for children's learning applications has several aspects, as shown in Fig. 3. Each aspect is distinguished based on the form of the application to be made. Application game aspects are user aspects, the context of use, pedagogical aspects, games aspect, and implementation aspects [26]. In the learning application, the type of games to be used are serious games. The reason for using this type is because serious games are tools that are considered useful in the learning process [27]. The material presented is distinguished based on thinking skills level ingame elicitation applications aimed at linking game mechanics that were commonly founded with learning mechanisms [25]. According to Piaget's, it was explained that children aged 6-8 years could have the ability to classify and understand ideas [28].

In non-game type applications, applications tend to be made in the form of simulations. Simulations can provide considerable learning potential because it is more effective and interactive [29] and can present material forms that convey the conditions of the situation in the real world [30]. The aspects are generic mobile environment issues, learning contexts, learning experiences, and learning objectives [31], as Fig. 3. The model of tools in Fig. 3 was implemented in the form of a mobile-based application. In the elicitation application that was built, all aspects of both types of applications will be accommodated. The selection of application types in the elicitation process was carried out at the beginning of the elicitation activity. The Requirements document can also be generated in this application. The aim is to facilitate and ease the elicitation team in verifying and validating requirements. Fig. 4 is a flowchart of the elicitation application that was built.

The VARK learning style implementation is applied to the elicitation applications that were built. The application is not only in the presentation of the material but also in the evaluation of the material. In presenting the material, children were given the opportunity to choose learning styles that suit their preferences. After the child listens to the material, then the evaluation is carried out. When evaluating given some questions related to the material have presented. Examples of problems can be seen in Table IV. The interaction of child answering questions was done according to the learning style chosen. Evaluation questions were presented according to the level of children's thinking skills. The flowchart of applying the VARK learning style can be seen in Fig. 5.
The implementation of elicitation tools that had been built in mobile-based applications. The application then tested on 32 children as respondents. Each child was asked to fill in each component by their preferences for each type of application. At the time of the presentation, the type of learning style was adjusted to the results of filling the VARK questionnaire given one week before the application testing process. The aim was made to facilitate the elicitation team in testing and assessing whether the learning style generated from the questionnaire is by the wishes of the child.

The results of filling out the questionnaire data can be seen in Table IV. From that data, a reliability test was performed using Cronbach's Alpha. The processing results obtained a value of 0.679 , so it can be said that this questionnaire has reliability. Then do the processing of the results of data filling by respondents to assess the satisfaction of the application user, and the results obtained Fig. 6.

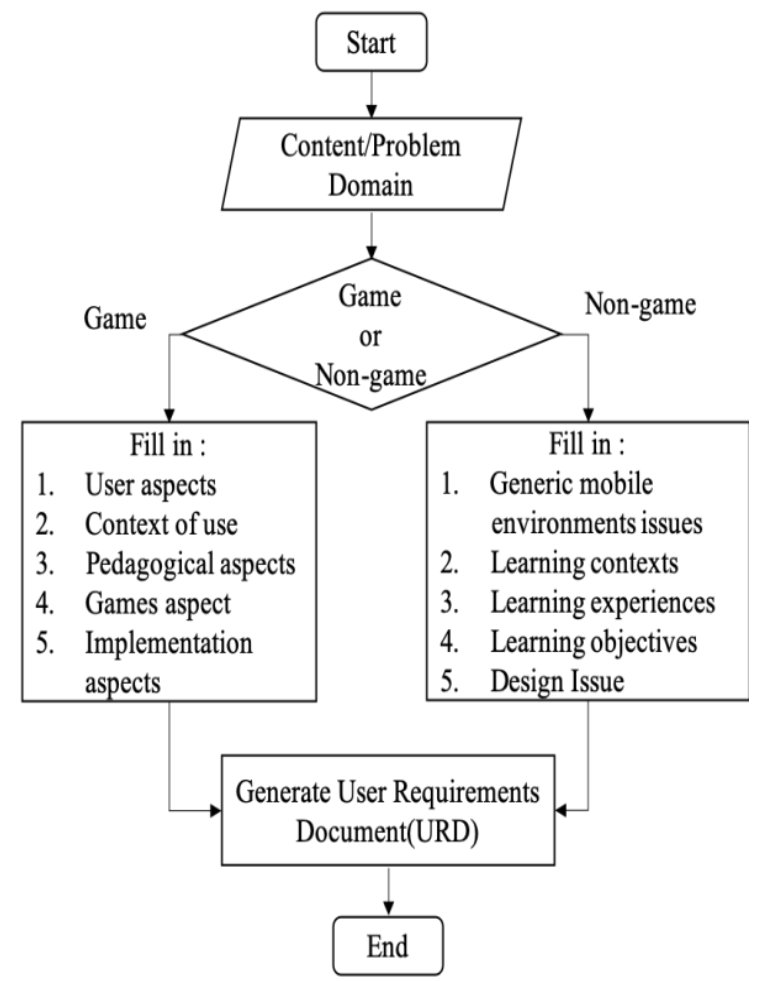

Fig. 4. Flowchart Model of Tools for Requirements Elicitation Process for Children's Learning Application 
TABLE. IV. EXAMPLES OF QUESTIONS TO MEASURE THINKING SKILLS LEVEL FOR CASE NON-GAME APPLICATIONS

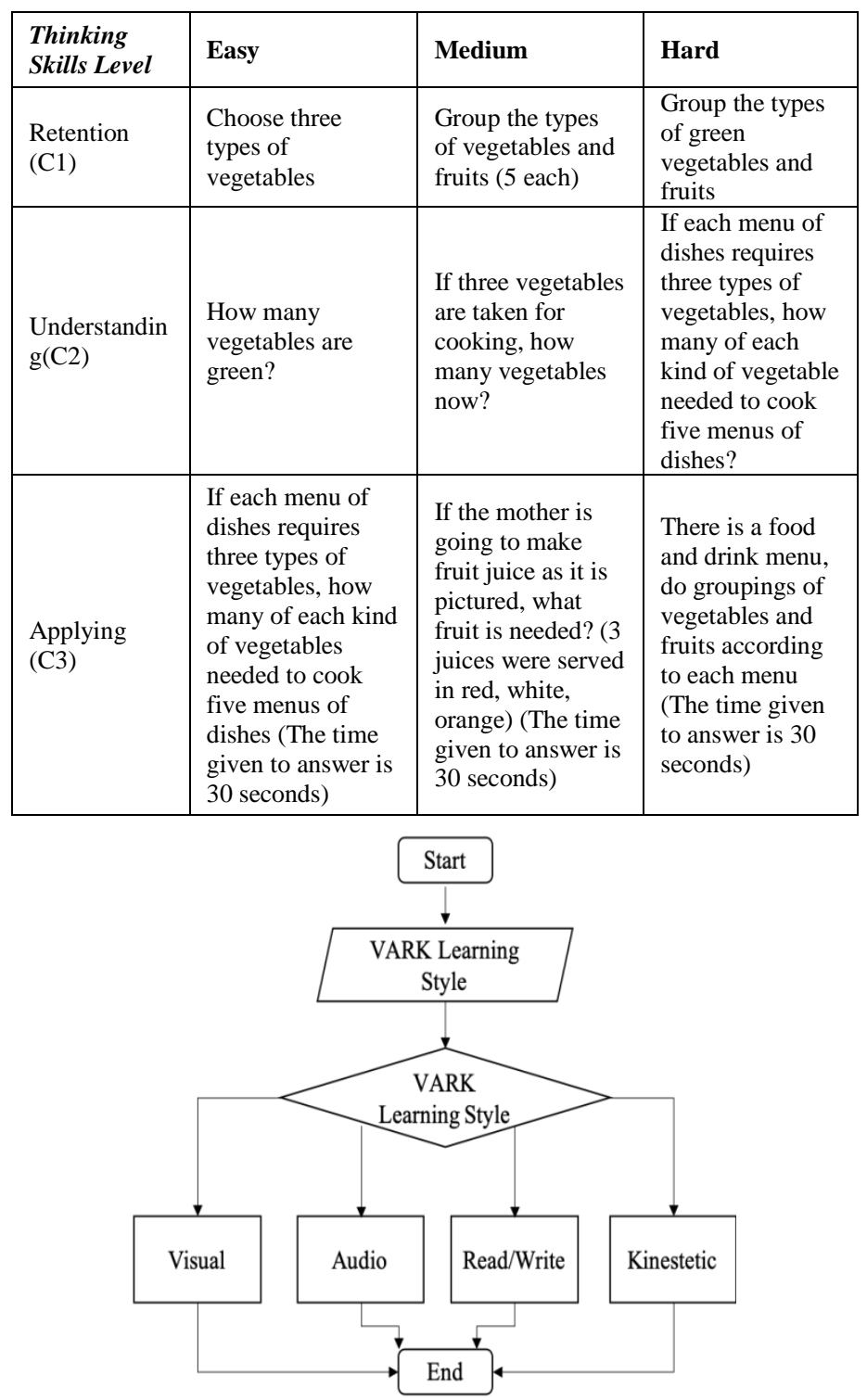

Fig. 5. Flowchart of Applying the VARK Learning Style.

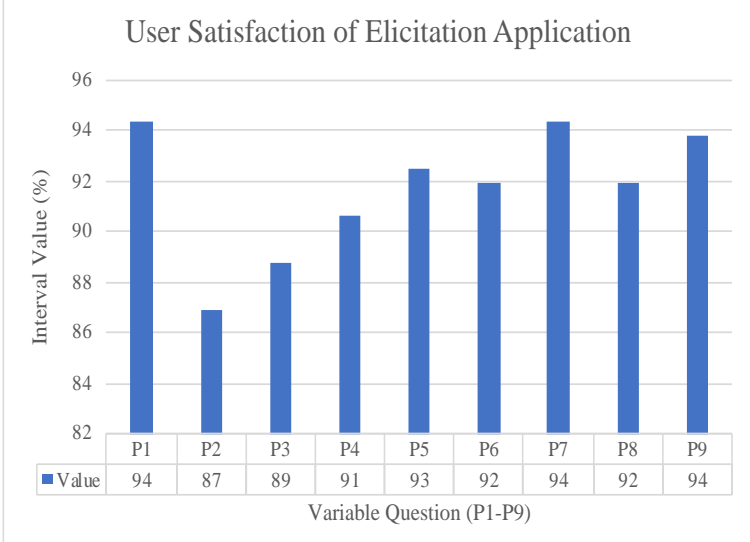

Fig. 6. Chart of user Satisfaction Assessment of Elicitation Applications.
Based on the results of processing, an interval analysis was performed to measure the satisfaction of the application. The results of the interval analysis can be concluded that each question (P1-P9) has a value $>=80 \%$ (strongly agree). In other words, the application of elicitation tools can be used by users well for each component of the question.

\section{CONCLUSION}

The conclusions that can be drawn from the results of this study are:

- The use of digital media was recommended making elicitation tools for children's learning software. This was evidenced by the non-parametric statistical tests using the Wilcoxon approach, which yields a value of 0.003 . That means that there are differences in interactions between the use of paper and digital in terms of time.

- The model of tools elicitation that was built has a satisfaction level $>=80 \%$. This means that children can express their desires on the learning application to be built. In other words, children's communication with the team can be done well.

Future work is to implement that elicitation tools model in real cases for children's learning applications

\section{ACKNOWLEDGMENT}

This research was supported by The Indonesia Endowment Fund for Education (Lembaga Pengelola Dana Pendidikan/LPDP).

\section{REFERENCES}

[1] Distanont and H. Haapasalo, "The Engagement between Knowledge Transfer and Requirements Engineering,” Int. J. Manag. Knowl. Learn., vol. 1, no. 2, pp. 131-156, 2012.

[2] L. C. Ronoh, G. M. Muchiri, and F. Wabwoba, "Factors affecting requirements elicitation for heterogeneous users of information systems," Int. J. Comput. Sci. Eng. Technol. IJCSET), vol. 5, no. 3, pp. 35-39, 2015.

[3] B. Davey and C. Cope, "Requirements Elicitation - What's Missing?," Proc. 2008 InSITE Conf., vol. 5, 2008.

[4] A. Ferrari, P. Spoletini, and S. Gnesi, "Ambiguity and tacit knowledge in requirements elicitation interviews," Requir. Eng., vol. 21, no. 3, pp. 333$355,2016$.

[5] N. C. L. Hess, D. J. Carlson, J. D. Inder, E. Jesulola, J. R. Mcfarlane, and N. A. Smart, Clinically meaningful blood pressure reductions with low intensity isometric handgrip exercise. A randomized trial, vol. 65 , no. 3 . 2016.

[6] M. Ivanov and P. D. Werner, "Behavioral communication: Individual differences in communication style," Pers. Individ. Dif., vol. 49, no. 1, pp. 19-23, 2010.

[7] A. De Lucia and A. Qusef, "Requirements engineering in agile software development," J. Emerg. Technol. Web Intell., vol. 2, no. 3, pp. 212-220, 2010.

[8] A. Davis et al., "Identifying and Measuring Quality in a Software Requirements Specification," in Software Metrics Symposium, 1993. Proceedings., First International, 1993, pp. 141-152.

[9] P. D. Chatzoglou and L. A. Macaulay, "Requirements capture and IS methodologies," Inf. Syst. J., vol. 6, no. 3, pp. 209-225, 1996.

[10] A. M. Aranda, O. Dieste, and N. Juristo, "Effect of Domain Knowledge on Elicitation Effectiveness: An Internally Replicated Controlled Experiment," IEEE Trans. Softw. Eng., vol. 42, no. 5, pp. 427-451, 2016. 
[11] H. F. Hofmann and F. Lehner, "Requirements engineering as a success factor in software projects," IEEE Softw., vol. 18, no. 4, pp. 58-66, 2001.

[12] C. K. Gonzales and G. Leroy, "Eliciting user requirements using Appreciative inquiry," Empir. Softw. Eng., vol. 16, no. 6, pp. 733-772, 2011.

[13] K. Siau and X. Tan, "Using cognitive mapping techniques to supplement UML and UP in information requirements determination," J. Comput. Inf. Syst., vol. 46, no. 5 SPEC. ISS., pp. 59-66, 2006.

[14] H. Al-Zawahreh and K. Almakadmeh, "Procedural model of requirements elicitation techniques," ACM Int. Conf. Proceeding Ser., vol. 23-25-Nove, 2015.

[15] N. Iivari, “'Representing the User' in software development-a cultural analysis of usability work in the product development context," Interact. Comput., vol. 18, no. 4, pp. 635-664, 2006.

[16] T. Nousiainen, "Children's Involvement in the Design of Game-Based Learning Environments Cases Talarius and Virtual Peatland," Des. Use Serious Games, vol. 37, pp. 49-66, 2009.

[17] S. Livingstone, "Reframing media effects in terms of children's rights in the digital age," J. Child. Media, vol. 10, no. 1, pp. 4-12, 2016.

[18] J. W. Santrock, Life-Span Development. The McGraw-Hill Companies, 2012.

[19] J. M. Carrillo De Gea, J. Nicolás, J. L. Fernández Alemán, A. Toval, C. Ebert, and A. Vizcaíno, "Requirements engineering tools: Capabilities, survey and assessment," Inf. Softw. Technol., vol. 54, no. 10, pp. 11421157, 2012.

[20] M. K. Sabariah, P. I. Santosa, and R. Ferdiana, "Selecting elicitation technique on requirements elicitation process: A case study on education application for children," in IOP Conference Series: Materials Science and Engineering, 2018, vol. 434, no. 1.
[21] J. E. Helmreich, "Statistics: An Introduction Using R (2nd Edition), " J. Stat. Softw., vol. 67, no. Book Review 5, 2015.

[22] S. M. Fisch, S. Damashek, and F. Aladé, "Designing media for crossplatform learning: Developing models for production and instructional design,” J. Child. Media, vol. 10, no. 2, pp. 238-247, 2016.

[23] J. Beatty and A. Chen, Visual Models for Software Requirements: An RML® Handbook. 2012.

[24] S. Cano, C. Collazos, H. M. Fardoun, and D. M. Alghazzawi, "Model Based on Learning Needs of Children," Int. Conf. Soc. Comput. Soc. Media, vol. 3, pp. 324-334, 2016.

[25] S. Arnab et al., "Mapping learning and game mechanics for serious games analysis," Br. J. Educ. Technol., vol. 46, no. 2, pp. 391-411, 2015.

[26] O. De Troyer and E. Janssens, "Supporting the requirement analysis phase for the development of serious games for children," Int. J. ChildComputer Interact., vol. 2, no. 2, pp. 76-84, 2014.

[27] A. Slimani, O. B. Yedri, F. Elouaai, and M. Bouhorma, "Towards a design approach for serious games," Int. J. Knowl. Learn., vol. 11, no. 1, pp. 58-81, 2016.

[28] R. D. Vatavu, G. Cramariuc, and D. M. Schipor, "Touch interaction for children aged 3 to 6 years: Experimental findings and relationship to motor skills," Int. J. Hum. Comput. Stud., vol. 74, pp. 54-76, 2015.

[29] L. Sha, C. K. Looi, W. Chen, P. Seow, and L. H. Wong, "Recognizing and measuring self-regulated learning in a mobile learning environment," Comput. Human Behav., vol. 28, no. 2, pp. 718-728, 2012.

[30] M. E. Gredler, Games and Simulations and Their Relationships to Learning. 2004.

[31] D. Parsons, H. Ryu, and M. Cranshaw, "A design requirements framework for mobile learning environments," J. Comput., vol. 2, no. 4, pp. 1-8, 2007. 